\title{
Queixa escolar e gênero: a (des)construção de estereótipos na educação*
}

\author{
Mariana Inés Garbarino' D
}

\section{RESUMO}

A prevalência de meninos no fracasso escolar vem sendo salientada por vários autores e o fenômeno vem se acrescentando com a incidência do diagnóstico de TDAH no sexo masculino. Com base em dados coletados em um programa de extensão para crianças com queixa escolar, o presente artigo visa contribuir com uma articulação teórico-empírica acerca da perpetuação dos estereótipos de gênero na educação. O método incluiu a análise de 142 fichas de matrícula, 172 protocolos de observação e 10 registros de rodas de conversa. Além do predomínio masculino no atendimento, identificaram-se indícios de clichês sexistas, notadamente a agressividade física e a impulsividade para os meninos, e o culto à beleza para as meninas. A pesquisa salienta o papel dos educadores na perpetuação dos estereótipos de gênero e a fecundidade das rodas de conversa como instrumentos para sua identificação e desconstrução.

\section{PALAVRAS-CHAVE}

fracasso escolar; estereótipos de gênero; educação sexual; rodas de conversa. 


\title{
SCHOOL COMPLAINT AND GENDER: THE (DES) CONSTRUCTION OF STEREOTYPES IN EDUCATION
}

\begin{abstract}
The prevalence of boys in school failure has been highlighted by several authors and the phenomenon has been added with the incidence of the diagnosis of ADHD in males. Based on data collected in an extension program for children with school complaints, this article aims to contribute to a theoretical-empirical articulation about the perpetuation of gender stereotypes in education. The method included the analysis of 142 registration cards, 172 observation protocols, and 10 conversation circles registers. In addition to the male predominance in the attendance, signs of sexist clichés were identified, especially the physical aggressiveness and impulsivity for the boys, and the cult of beauty for the girls. The research emphasizes the role of educators in the perpetuation of gender stereotypes and the fertility of conversation circles as instruments for their identification and deconstruction.
\end{abstract}

KEYWORDS

school failure; gender stereotypes; sexual education; conversation circles.

\section{QUEJA ESCOLAR Y GÉNERO: LA (DES)CONSTRUCCIÓN DE ESTEREOTIPOS EN LA EDUCACIÓN}

\section{RESUMEN}

La prevalencia de varones en el fracaso escolar viene siendo resaltada por varios autores y el fenómeno aumenta con la incidencia del diagnóstico de TDAH en el sexo masculino. Con base en datos recogidos en un programa de extensión para niños con queja escolar, el presente artículo tiene como objetivo contribuir con una articulación teórico-empírica acerca de la perpetuación de los estereotipos de género en la educación. El método incluyó el análisis de 142 fichas de matrícula, 172 protocolos de observación y 10 registros de ruedas de conversación. Además del predominio masculino en el programa, se identificaron indicios de clichés sexistas, notadamente la agresividad física e impulsividad para los niños, y el culto a la belleza para las niñas. La investigación subraya el papel de los educadores en la perpetuación de los estereotipos de género y la fecundidad de las ruedas de conversación como instrumentos para su identificación y deconstrucción.

fracaso escolar; estereotipos de género; educación sexual; ruedas de conversación. 


\section{INTRODUÇÃO}

A prevalência de meninos no fracasso escolar foi salientada por vários estudos (Carvalho, 2001,2003, 2004, 2012; Fernandez, 2006 apud Marangon, 2006; Borsa, Souza e Bandeira, 2011; Emerich et al.,2012), e o fenômeno vem se acrescentando com a prevalência do diagnóstico de transtorno de déficit de atenção/hiperatividade (TDAH) no sexo masculino (Rohde e Halpern, 2004; Siqueira e Gurgel-Giannetti, 2011; Rezende, 2013). No entanto, a explicação do porquê os meninos fracassam mais do que as meninas na escola ainda não é consenso.

O mapeamento da complexidade dos fatores envolvidos na construção histórica das identidades de gênero permite entender melhor alguns dados alarmantes da realidade escolar brasileira. No ano de 2015, o Censo Escolar apontou um total 3 milhões de crianças e jovens entre 4 e 17 anos fora da escola. Nesse mesmo ano, 1,6 milhão de alunas e alunos que apareciam matriculados no Censo de 2014 abandonaram a instituição escolar, sendo denominados pelo Ministério da Educação e Cultura (MEC) como "invisíveis" (Tokarnia, 2016). O perfil majoritário dos estudantes era de sexo masculino, negros e de escolas urbanas.

Esse perfil prevalente converge com as estatísticas que revelam os três fatores da composição de alunas e alunos que mais impactam no Índice de Desenvolvimento da Educação Básica (Ideb) ${ }^{1}$ : nível socioeconômico, cor/raça e gênero (Alves e Soares, 2013). Ainda que o nível socioeconômico seja o fator de maior impacto, gênero e cor/raça também são elementos significativos (Alves e Soares, 2013). Entretanto, segundo Carvalho (2004), poucos são os estudos de gênero que consideram suas relações com esses outros fatores sociais, o que acaba reduzindo a complexidade do fenômeno do fracasso escolar. Nesse sentido, a autora constatou que, em comparação com os meninos, as meninas costumam ser menos identificadas pelos professores a partir de seu perfil racial (Carvalho, 2004).

Embora as pesquisas sobre preconceitos de gênero no contexto escolar venham se desenvolvendo há mais de duas décadas (Guimarães, 1995; Camargo e Ribeiro, 1999; Nunes e Silva, 2000; Figueiró, 2009; Madureira e Branco, 2015), sua relação com os transtornos da aprendizagem é mais incipiente. $O$ fenômeno é saliente para pensar de que modo o gênero permeia a queixa escolar. Durante os primeiros anos do ensino fundamental, o principal motivo de consulta psicológica consiste em demandas ligadas à escolaridade que contemplam queixas por problemas de adaptação e de aprendizagem (Lenoble, 2010; Zulueta, 2010). Nesses atendimentos de saúde mental, corrobora-se a maior proporção de meninos. Por exemplo, das 551 crianças e adolescentes de 6 a 14 anos atendidas em 1997 no Ambulatório do Serviço de Psiquiatria da Infância e da Adolescência do Instituto de Psiquiatria do Hospital das Clínicas da Faculdade de Medicina da Universidade de São Paulo (Sepia), 386 (70\%) eram meninos e 165, meninas (30\%), o que confirmou uma diferença significativa da variável sexo (Lee e Matarazzo, 2001).

1 Criado em 2007 pelo Instituto Nacional de Estudos e Pesquisas Educacionais Anísio Teixeira (Inep), formulado para medir a qualidade da aprendizagem nacional e estabelecer metas para a melhoria do ensino. 
Atualmente, essa primazia masculina está associada ao TDAH, transtorno do neurodesenvolvimento intimamente correlacionado à queixa escolar (Bonadio e Mori, 2013; Bianchi e Faraone, 2015; Janín, 2004). A literatura que trata do perfil desse polêmico diagnóstico verifica maior prevalência nos meninos e as proporções segundo o sexo variam entre: aproximadamente 2:1 (em estudos populacionais) e até 9:1 (em estudos clínicos) (Rohde e Halpern, 2004). Observa-se maior presença de sintomas hiperativos nos meninos, enquanto as meninas apresentam mais o tipo desatento (Siqueira e Gurgel-Giannetti, 2011; Rezende, 2013). Em função disso, a sintomatologia externalizante dos meninos causa mais encaminhamentos da escola e/ou mais preocupação dos pais pela tensão gerada na convivência familiar. Essa diferença de gênero no TDAH concorda com a distribuição das tendências de comportamentos internalizantes em meninas e externalizantes em meninos (Emerich et al., 2012). Entretanto, essa discrepância geral de gênero resulta ainda controversa e sem consenso na literatura (Borsa, Souza e Bandeira, 2011).

A relação entre gênero e fracasso escolar foi abordada por Carvalho (2003, 2004) e por Carvalho, Senkevics e Loges (2014), que analisou as causas da prevalência dessa condição em meninos. Um dos pressupostos habituais para explicar a questão é o trabalho infantil majoritário em crianças de sexo masculino. Contudo, essa justificativa não seria pertinente, já que as meninas, em compensação, trabalham mais em serviço doméstico ou cuidando de irmãos mais novos (Carvalho, 2003). O estereótipo de meninas tranquilas e dóceis e meninos indisciplinados e desorganizados também não explicaria essa diferença. Sem chegar a conclusões definitivas, Carvalho (2003) e Carvalho, Senkevics e Loges (2014) apontam a um imaginário de masculinidade no qual o menino que vai bem na escola ou que é elogiado pela professora "acaba sendo desprezado pelos colegas, chamado de 'bicha' ou de 'mulherzinha', e para afirmar sua masculinidade acaba tendo que recorrer até ao mau desempenho escolar, à indisciplina" (Carvalho, 2003, p. 191).

Desde outro ângulo, algumas autoras destacam que a menina seria mais sensível ao olhar do outro e, com base nessa maior necessidade de aprovação do que o menino, deslocaria seu desejo de integridade e estética nas aprendizagens escolares (Arbisio, 2007). Também conforme Janín (2004), o valor da estética tem pesos diferentes em meninos e meninas, o que explicaria os cadernos caprichados que elas mostram com orgulho procurando a aprovação dos adultos. Já os meninos rejeitam a ideia de ficar em uma atitude passiva de obediência e tendem a responder e "desafiar" o outro, ativo e poderoso, para evitar uma posição feminina (Janín, 2004). Desse modo, o problema da disciplina se coloca para o menino como uma luta pelo poder e, assim sendo, para ele seria melhor ser visto como líder no grupo do que como bom aluno, o que converge na linha de interpretação de Carvalho $(2003,2004)$ já mencionada.

Fernandez (2006 apud Marangon) coloca o foco da questão no universo feminino prevalente do professorado e sublinha que, no ciclo I do ensino fundamental, mais de $95 \%$ dos profissionais são mulheres. Conforme a autora, isso causaria dificuldades de identificação dos meninos com as professoras e seria um obstáculo para a significação prazerosa do conhecimento. Em concordância com esse raciocínio, a pesquisa de Sleator e Ullman (apud Janín, 2004) comprovou que crianças 
com diagnóstico de TDAH amenizam a expressão da sintomatologia hiperativa em contextos de interação com figuras de autoridade masculina em vez de feminina.

Em síntese, a literatura identifica que, além de raça e classe, o fracasso escolar é permeado pelo fator gênero. Mas o tema é incipiente e não há ainda consenso para explicar a prevalência masculina. Entretanto, há convergências na observação da presença de estereótipos de gênero no contexto educativo, tanto familiar como escolar (Le Maner, 1997; Brougère, 1999; Moreno, 1999; Reis e Maia, 2009; Cechin e Silva, 2012; Madureira e Branco, 2015).

Considerando-se que as pesquisas sobre gênero e fracasso escolar dão pouco protagonismo às próprias crianças (Carvalho, 2004), o objetivo deste artigo é suprir parcialmente essa lacuna dando-lhes voz. Desse modo, a partir de um lócus "micro" de atendimento, pretende-se enfatizar um ponto que não teve devida atenção e não foi suficientemente pesquisado: a interpretação das crianças protagonistas da queixa. Situando-se nas coordenadas do macrocontexto do fracasso escolar, o trabalho visou caracterizar e ilustrar a tendência da interface gênero $\times$ queixa indagando se seria possível identificar diferenças nas produções discursivas e ações de meninos e meninas. Em termos metodológicos, o estudo propõe o instrumento de rodas de conversa para fomentar a expressão de ideias e os sentimentos acerca dos estereótipos de gênero e dos conflitos escolares.

Antes de passar aos dados encontrados na pesquisa, no intuito de avançar na discussão acerca do sexismo na base da queixa escolar, serão sistematizados três prismas de análise da presença e perpetuação da educação sexista na infância que contribuem para sua desnaturalização, salientando-se seu caráter social e histórico:

- a discussão genética $\times$ ambiente na construção da identidade de gênero;

- as escolhas sexistas de jogos e brincadeiras;

- a força do tabu da diversidade sexual na escola.

\section{ESTEREÓTIPOS DE GÊNERO NA EDUCAÇÃO}

O mapeamento da discussão sobre a construção dos comportamentos de gênero na dialética genética-ambiente evidencia que, na contramão das explicações naturalistas e biologizantes das discrepâncias do ser menino $\times$ ser menina, prepondera a hipótese etiológico-cultural que remete aos aspectos de criação que influenciam a construção das identidades de gênero (Le Maner, 1997; Parisotto et al., 2003). Esses trabalhos do âmbito da psicologia das diferenças sexuais e de gênero convergem em apontar que é a educação familiar e escolar a que continua reforçando certos padrões de conduta ao longo do desenvolvimento (Le Maner, 1997; Reis e Maia, 2009). A partir de entramados conceituais de diferentes perspectivas teóricas, a construção das identidades de gênero é explicada, em parte, pelas atitudes comunicativas e afetivas desiguais dos adultos primários (familiares ou escolares) conforme sejam direcionadas, desde o nascimento, aos meninos ou às meninas (Moreno, 1999; Reis e Maia, 2009; Madureira e Branco, 2015).

Além dessas questões culturais, identificam-se diferenças no prisma neurofuncional e endócrino: por exemplo, a maior agressividade nos homens correlacionada a maiores níveis de testosterona (Westly, 2012). Entretanto, os estudos das 
neurociências apontam que, mesmo havendo leves diferenças anatômicas endócrinas e cerebrais, o papel do entorno é capital no desenvolvimento de certas habilidades mediante ofertas seletivas de objetos segundo o gênero (Cahill, 2012). O ambiente reforça, por exemplo, o desenvolvimento desigual das habilidades espaciais, sendo uma capacidade levemente diferenciada em favor dos homens no plano genético, mas altamente exacerbada na oferta de brinquedos e jogos "de meninos e de meninas". Em resumo, é a experiência que muda o cérebro pelo mecanismo de plasticidade cognitiva e o modo de criação do indivíduo constitui uma "infusão de gênero cultural" (Cahill, 2012).

Os estudos contemporâneos acerca dessa "infusão cultural" destacam que a cultura demanda responder a identidades de gênero, com modelos de masculinidade ligados à agressividade e aos riscos (Le Maner, 1997). Já os femininos estão mais relacionados ao "ser bela", via controle do peso e cuidado do corpo, das unhas e do cabelo (Arbisio, 2007; Gutton, 2009). O império rosa e banal de Barbie e de outras bonecas similares permanece sendo um fenômeno crescente em vendas, promovendo o culto à vaidade, à riqueza e ao corpo perfeito branco, loiro, magro e ocidental (Cechin e Silva, 2012).

As escolhas infantis de jogos e brinquedos são propiciadas pelas experiências lúdicas diferenciais que os adultos oferecem (intencionalmente ou não) e, na maioria das vezes, respondem a estereótipos de gênero (Le Maner, 1997; Brougère, 1999; Reis e Maia, 2009). Ademais, o público infantil continua sendo o destinatário de clichês fomentados pela indústria dos brinquedos que fortalece os lugares-comuns do sexismo com a clássica divisão de produtos para meninas e para meninos. Os primeiros continuam relacionados a temáticas domésticas e de cuidados maternos (Le Maner, 1997; Moreno, 1999). No caso dos brinquedos "para meninos", proliferam carrinhos, armas e bonecos lutadores que evocam aparatos militares de guerra, fomentando o estereótipo da agressividade (Brougère, 1999; Figueiró, 2009).

A respeito das meninas, vários autores contemporâneos vêm assinalando sua sexualização precoce, que traz como efeito o abandono de brincadeiras e jogos para usar maquiagem, roupa adulta e começar a se interessar por meninos cada vez mais cedo (Arbisio, 2007; Urribarri, 2012). O fenômeno da sexualização precoce das meninas é fomentado pela mídia e por uma educação frágil em tempos em que a autoridade, as diferenças geracionais e os limites vão sendo diluídos (Steibel et al., 2011; Souza, 2014).

Acerca dos conteúdos do jogar, historicamente houve diferenças nas escolhas de brinquedos e jogos mais relacionados a um ou outro gênero, fato ilustrado no caso da sinuca, que foi mal vista entre as mulheres até algumas décadas atrás (embora esse tom pejorativo possa ainda persistir). Pesquisas atuais que abordam as tendências no uso dos videogames também mostram preferências diferenciadas nas escolhas feitas por homens e mulheres segundo tipos de jogos escolhidos e habilidades (Alves e Carvalho, 2011; Suzuki et al., 2009). Nesse sentido, um estudo com crianças evidenciou a preferência masculina pelo "futebol" e o "videogame" e observou que a interpretação de "jogo violento" foi um dos argumentos femininos para rejeitá-los no seu repertório lúdico (Rossetti e Souza, 2005). 
Já o campo da literatura infantil vem protagonizando um papel transgressor em torno da desconstrução desses estereótipos sexistas. Nos últimos anos, tem surgido uma vasta produção internacional que aborda essa temática em histórias para crianças e adolescentes. Elas apresentam princesas independentes que não querem se casar e preferem atividades historicamente destinadas aos homens, assim como príncipes que gostam de cozinhar e não se mostram sempre fortes e valentes. A crescente presença de famílias homoparentais nos contos também interroga esses papéis sexuais clássicos (Silveira e Kaercher, 2013).

Entretanto, ainda quando a orientação sexual era um tema transversal do currículo, a diversidade sexual gerava, e continua gerando, fortes resistências no âmbito escolar (Cadete, Ferreira e Silva, 2012). O eixo “orientação sexual” foi incorporado, em 1997, nos Parâmetros Curriculares Nacionais (PCNs) desde o ciclo I do ensino fundamental. A partir da sua inserção no currículo e em projetos de formação de professores, o sexismo e a diversidade de identidades de gênero eram abordados em seu estatuto de "tema transversal" (Vianna, 2012; Madureira e Branco, 2015). Vários pesquisadores realizaram uma leitura crítica do antigo documento curricular, ressaltando sua abordagem naturalista com base em uma concepção biológica que deixava de lado a diversidade sexual e os valores socioculturais que permeiam o sexismo (Altmann, 2001; Vianna, 2012). Apesar dessas críticas, a orientação sexual foi um importante avanço em matéria de oficializar a temática no contexto escolar, mas acabou sendo suprimido na nova Base Nacional Comum Curricular (BNCC) de 2019.

A supressão do tema na nova BNCC foi um retrocesso, considerando-se que os dados sobre situações de violência relacionadas com preconceitos sexuais continuam sendo alarmantes. A Pesquisa Nacional sobre o Ambiente Educacional no Brasil (2016) verificou que 73\% dos estudantes LGBT já foram atacados verbalmente e 36\% foram agredidos fisicamente na escola (apud Tokarnia, 2016). Os desafios colocados pelas novas configurações familiares e os direitos da população LGBT tornam impostergável a reincorporação da orientação sexual como tema transversal no cotidiano escolar (Vianna, 2012). A estrutura homoparental, por exemplo, ainda é fortemente rejeitada em seu estatuto de família, o que corresponde com a ausência do tema na escola (Cadete, Ferreira e Silva, 2012).

No campo acadêmico, entretanto,já faz mais de duas décadas que as pesquisas sobre educação sexual discutem os aspectos sócio-históricos do sexismo focando, notadamente, os preconceitos de professores e pais, os estereótipos fomentados pelas escolas, a vulgarização da sexualidade humana na mídia e a ausência ou distorções de explicações sobre as diferenças sexuais, os papéis de gênero e a reprodução humana (Guimarães, 1995; Camargo e Ribeiro, 1999; Nunes e Silva, 2000; Figueiró, 2009; Madureira e Branco, 2015). No que diz respeito às representações acerca da sexualidade, prevalece o estudo das crenças e dos discursos dos adultos, sejam professoras, professores e/ou pais (Altmann, 2009; Madureira e Branco, 2015). Observa-se que na instituição escolar existem posições diversas do professorado, que funciona como prolongamento da família e reforço de seus valores, como meio de abertura de horizontes para a criança na linha de sua emancipação, ou como agente moralizador (Guimarães, 1995). 
Os discursos das professoras e dos materiais didáticos não são neutros na construção dos estereótipos de gênero (Madureira e Branco, 2015). A escola colabora para os modos de subjetivação das crianças reproduzindo os discursos imperantes em cada época histórica (Moizés e Bueno, 2010). O clássico Como se ensina a ser menina, de Monserrat Moreno (1999), foi um dos pioneiros em discutir essa questão em detalhe, mostrando de que modo o sexismo se reproduz na práxis escolar. Em relação aos livros didáticos, a associação da mulher às tarefas domésticas e do homem como "provedor" tem diminuído (Moreno, 1999), em parte, como reflexo do âmbito laboral: ainda que as mulheres sigam dedicando mais tempo aos serviços domésticos do que os homens, observam-se deslocamento das fronteiras do masculino e do feminino e significativas modificações nas modalidades dessa divisão (Hirata, 2002).

Contudo, a sexualidade perpetua-se como uma dimensão das relações de poder entre jovens e velhos, pais e filhos, educadoras, educadores e estudantes (Vianna, 2012). Historicamente, os contextos da infância (escola, família, mídia etc.) constituem dispositivos de poder e controle permeados pelas chamadas "políticas sexuais" que, por diferentes meios, reduzem a sexualidade "à sua função reprodutiva, à sua forma heterossexual e adulta e à sua legitimidade matrimonial" (Foucault, 2010, p. 114).

Nessa mesma lógica, a subjetividade infantil resulta atravessada pelo discurso institucional que nomeia e justifica o desempenho escolar das crianças (Guarido, 2007; Osti e Brenelli, 2013; Bautheney, 2011). Essa circulação das explicações acerca da competência e da dificuldade para aprender está silenciosamente atrelada às representações de gênero instituídas no cotidiano escolar (Carvalho, 2003; Fernandez, 2006 apud Marangon, 2006). Progressivamente, essa nomeação do sujeito matriziada conforme os clichês sexistas acaba sendo aprendida e internalizada pelas alunas e pelos alunos.

A seguir, esses estereótipos são assinalados e discutidos a partir dos resultados de uma pesquisa empírica realizada em um programa de extensão para crianças com queixa escolar. A análise de dados objetivou identificar possíveis tendências diferenciais de meninos e meninas diante de conflitos cognitivos e intersubjetivos. Além disso, propõe-se o uso de rodas de conversa como instrumento pedagógico fértil para a identificação e a desconstrução dos estereótipos de gênero.

\section{O TERRENO DISCURSIVO DAS CRIANÇAS: APROXIMAÇÕES E TRILHAS DA PESQUISA}

O trabalho foi realizado no contexto de um programa de extensão universitário ${ }^{2}$ que realiza intervenções com crianças com queixa escolar. Os participantes, de 7 a 11 anos, frequentam, majoritariamente, escolas públicas ou fundações. $\mathrm{O}$ atendimento é grupal, conformado geralmente por 8 a 10 participantes, com duração de três semestres e encontros semanais de uma hora. Utilizam-se jogos lógico-matemáticos e de comunicação (individuais, em duplas ou grupais) bem

2 Programa de atendimento para alunos do ensino fundamental oferecido pelo Laboratório de Estudos do Desenvolvimento e da Aprendizagem, no Instituto de Psicologia da Universidade de São Paulo (LEDA/USP). 
como situações-problema que exigem diferentes estratégias de resolução. A segunda parte dos encontros se estrutura no dispositivo de rodas de conversa sobre temáticas diversas relacionadas aos âmbitos escolar e familiar.

A demanda com que a criança chega aos atendimentos é diversificada conforme a prevalência de dificuldades na alfabetização e/ou matemática, queixas por dispersão, falta de interesse, desatenção, problemas de relacionamento e disciplina, bem como os diagnósticos de transtornos específicos ou síndromes (suspeita ou diagnóstico de TDAH, dislexia etc.). A pesquisa foi submetida ao Comitê de Ética em Pesquisa com Seres Humanos (CEPH) da USP, sendo aprovada pelo parecer $\mathrm{n}^{\circ}$ 1.082.789.

Os materiais obtidos dos arquivos são referentes ao primeiro semestre de participação de 35 crianças (15 meninas e 20 meninos). Tentou-se aproximar a quantidade de meninos e meninas, mas esta não foi equiparada, fato que deriva da prevalência do sexo masculino na procura do atendimento, tal como será mostrado nos resultados. No total, foram analisados sete semestres, do período 2011-2014, em que a pesquisadora foi membro da equipe. Para a coleta de dados, foram consultados três tipos instrumentos: 142 fichas de matrícula com motivos de inscrição, 172 protocolos de observação e 10 registros escritos de rodas de conversa.

Os dados foram organizados conforme as recorrências e convergências observadas em meninos e meninas. A análise foi qualitativa e quantitativa. No primeiro caso, foram contemplados os 172 protocolos sistematizando os itens marcados na observação de três momentos: o afrontamento da proposta, a interação global com a tarefa e a resolução dos conflitos cognitivos. Da marcação total de 1.385 itens, foram considerados os 5 que manifestaram maior discrepância de gênero: envolvimento, impulsividade, fuga - dispersão, rapidez para começar e autonomia.

Já os registros escritos das rodas de conversa foram abordados qualitativamente, conforme a análise de conteúdo (Castro, Abs e Sarriera, 2011). No caso da temática "resolução de conflitos intersubjetivos", os dados foram sistematizados em tipos de modalidades prevalentes segundo a predominância de respostas físicas ou simbólicas. Tanto nos protocolos de observação de modalidades do jogar como nos registros escritos das rodas de conversa foram consideradas produções verbais e não verbais que envolvessem gestos, olhares, movimentos, expressões faciais etc.

\section{A (DES)CONSTRUÇÃO DO SEXISMO: RESULTADOS, ANÁLISES E REFLEXÕES}

Em relação ao perfil de gênero da população dos atendimentos, a análise de 142 fichas de matrícula confirmou que quase o triplo dos participantes eram meninos. Esse dado corroborou a prevalência masculina citada na literatura acerca do fracasso escolar e da demanda por atendimento em instituições de saúde mental. A porcentagem de inscrições ${ }^{3}$ em cada semestre do período 2011-2014, segundo o sexo, pode ser observada na Tabela 1 .

3 Cabe ressaltar que o número de inscrições não corresponde ao número de crianças, já que uma mesma criança pode se inscrever nas oficinas por até três semestres consecutivos. 
Tabela 1 - Distribuição de inscrições no período 2011-2014 segundo o sexo.

\begin{tabular}{|l|c|c|}
\hline & Frequência absoluta & Frequência relativa (\%) \\
\hline Meninos & 102 & 71 \\
\hline Meninas & 42 & 29 \\
\hline Total & 142 & 100 \\
\hline
\end{tabular}

Fonte: adaptado de Garbarino (2017).

As diferenças de gênero nas formas de resolução de conflitos cognitivos foram abordadas na análise quantitativa (não estatística) dos 172 protocolos de observação de ações. Os achados são apresentados no Gráfico 1. Observa-se que os procedimentos diante dos conflitos cognitivos propiciados pelos jogos e pelas situações- problema manifestaram poucas divergências em meninos e meninas. Ainda assim, a frequência de todos os itens é maior entre os meninos: envolvimento (19\% a mais) e impulsividade (16\% a mais), seguidas de dispersão (14\% a mais) e rapidez para comę̧ar (13\% a mais). Considerando-se que esses procedimentos e atitudes estão bastante correlacionados, é preciso que sejam considerados em conjunto. Por exemplo, embora os meninos tenham mostrado maiores indícios de envolvimento, o fato de estarem envolvidos não levava, necessariamente, a procedimentos de resolução de melhor qualidade, em comparação com as meninas.

Gráfico 1 - Distribuição percentual de recorrências de resolução segundo o sexo.

fuga ou dispers ão

envolvimento

autonomia

impuls ividade

rapidez para começar
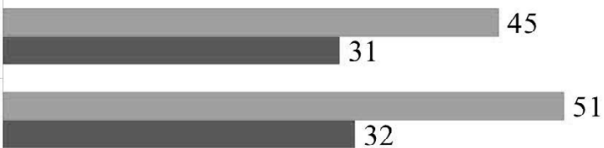

meninos

meninas

Fonte: adaptado de Garbarino (2017).

A maior impulsividade observada nos meninos envolveria reações de automatismo e imediatez, atitudes cognitivas que se situam na antítese da reflexão (Houdé, 2014). Esse achado converge com a literatura sobre o diagnóstico de TDAH, que tem mostrado maiores índices de desatenção para as meninas e hiperatividade nos meninos (Siqueira e Gurgel-Giannetti, 2011; Rezende, 2013). A divergência foi constatada nas observações sobre impulsividade, mas não sobre dispersão, que também 
foi maior nos meninos. Além disso, a constatação de maiores índices de envolvimento e autonomia (11\% a mais) a favor deles pode também estar relacionada com a prevalência da rapidez para comę̧ar (13\% a mais). Em síntese, embora tenham sido identificadas algumas distinções na resolução de conflitos cognitivos, elas resultam pouco expressivas e não permitem concluir em modalidades femininas e masculinas.

A análise qualitativa referente ao dispositivo das rodas de conversa indagou possíveis divergências de gênero em matéria de diversas temáticas, tais como: conflitos intersubjetivos com pares; preferências lúdicas; diferenças entre meninos e meninas; e projeção profissional. Cabe assinalar que as rodas de conversa constituem uma metodologia amplamente utilizada com adolescentes e adultos no âmbito da saúde (Sampaio et al., 2014; Branco e Pan, 2016; Melo et al., 2016), mas os estudos com crianças no âmbito escolar ainda são escassos. Entretanto, sua riqueza pedagógica é vasta por possibilitar que a criança, usufruindo do espaço de circulação da palavra, vivencie um novo modo de autovalorização como sujeito crítico pensante em uma posição mais autônoma, descentrada e flexível, não só com os objetos de conhecimento, mas também nas suas relações interpessoais nos contextos escolar e familiar.

Para abordar as modalidades de resolução de conflitos intersubjetivos com colegas, foram analisadas as produções discursivas acerca da questão: "o que você faz quando alguém te provoca ou tira sarro de você?”. Cabe mencionar que, conforme as respostas dadas, não se deduz que a criança realmente fez ou faz aquilo que diz. Elas são analisadas identificando-se tendências prevalentes de atribuição de sentido sobre a ação (sejam realistas ou fantasiosas), e não a própria ação de resolução.

Após a leitura exaustiva de 28 respostas, elas foram sistematizadas de acordo com o reconhecimento (ou não) de uma instância de regulação social externa ao indivíduo que perpassasse a resposta física. Identificaram-se três modalidades ${ }^{4}$ preponderantes de regulação na interpretação do conflito:

- retração ou inibição da ação: a criança manifesta desinvestimento da situação, via retração, tentativa de fugir ou anular o conflito;

- agressão física irruptiva: a perturbação é investida massivamente com o corpo, sendo irruptiva por envolver a invasão ou o transbordamento súbito de sentimento;

- mediação simbólica: o sujeito apela à palavra, à regra, ou procura a mediação do adulto.

Tal como exposto no Quadro 1, as produções discursivas evidenciaram discrepância de gênero na segunda categoria de resolução do conflito apelando ao corpo. Nenhuma menina fez menção a esse tipo de estratégia, já que as 16 menções à regulação física foram feitas por meninos. Cabe destacar que, durante a fala, eles costumavam rir ou procurar um olhar de cumplicidade nos colegas. Ainda que a enunciação não reflita a ação verdadeiramente realizada, a produção discursiva

4 Escolhemos falar de modalidades, e não de estágios nem níveis, para evitar dar um caráter hierárquico às produções discursivas e salientar as tramas de significações em torno do conflito conforme sejam produzidas por meninos ou meninas. 
Quadro 1 - Categorização das respostas sobre resolução de conflitos intersubjetivos.

\begin{tabular}{|c|}
\hline Retração ou inibição da ação \\
\hline $\begin{array}{l}\mathrm{Ca}(\mathrm{M})^{5} \text { "não faço nada e vou para outro lugar" / } \mathrm{Mi}(\mathrm{F}) \text { "finjo que não prestei atenção" / La (F) "não ligo" / } \\
\mathrm{Lar}(\mathrm{F}) \text { "eu corro" / Gui }(\mathrm{M}) \text { "fiquei quieto [pediu ajuda?] não" / } \mathrm{H}(\mathrm{M}) \text { "Ignoro". }\end{array}$ \\
\hline Agressão física irruptiva \\
\hline 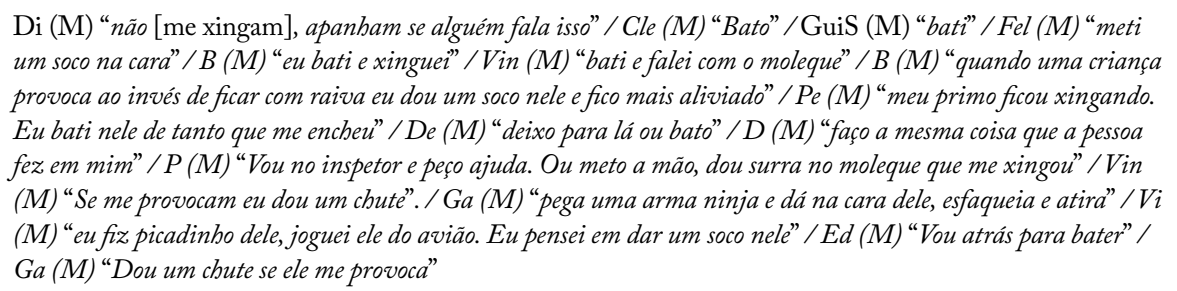 \\
\hline Mediação simbólica \\
\hline $\begin{array}{l}\mathrm{Fe}(\mathrm{M}) \text { "Pedi para pararem e eles pararam" / Ja (F) "mando calar a boca" / Le (F) "eu fico triste e bem } \\
\text { nervosa. Eu falo para a professora" / Th }(\mathrm{M}) \text { "mando calar a boca e conto para prô" / Am (F) "falei com a } \\
\text { professora" / Lu (M) "um menino de minha classe me chama de 'gorducho' e gordo tapete velho. Pedi ajuda para } \\
\text { a professora, mas ele mente e diz que não falou nada" }\end{array}$ \\
\hline
\end{tabular}

Fonte: adaptado de Garbarino (2017).

responde a um estereótipo de masculinidade no qual a agressão física é esperada e, no pior dos casos, celebrada e legitimada. Já no caso das meninas, predominou a inibição da ação ou a mediação simbólica.

A tendência masculina de preferência lúdica pelos videogames violentos também foi verificada em expressões como: Gu (M) "Tiro? Sangue? Luta? Gosto porque desconta a raiva" / Wa (M) "gosto é da hora matar os carinhas" / $\mathrm{Cl}(\mathrm{M})$ "gosto porque é da hora".

Já as meninas tenderam a rejeitar esses tipos de jogos, o que fica ilustrado nos seguintes exemplos: $\mathrm{La}(\mathrm{F})$ "não gosto porque é chato" / Am (F) "não gosto, não é legal" /Ja (F) "meu preferido é o twister" / Is (F) "não gosto de nada violento, às vezes eu tinha pesadelo com os jogos do meu irmão".

Ainda com clara divergência, a divisão de preferências lúdicas não é taxativa, encontrando rejeição também em meninos: $\mathrm{Di}(\mathrm{M})$ "odeio porque incentiva as pessoas a bater". Similarmente, algumas meninas manifestaram interesse pelo futebol: $\mathrm{La}(\mathrm{F})$ queixou-se porque quer aprender jogar "mas os meninos não deixam", $\mathrm{Ma}(\mathrm{F})$ diz que ela é boa jogando futebol e $\mathrm{Be}(\mathrm{F})$ diz que quando crescer quer ser "dançarina de dança do ventre ou jogadora de futebol". Apesar disso, observou-se que o futebol é hegemônico nas escolhas dos meninos e em seus projetos futuros de jogadores profissionais.

5 As falas estão em itálico e os participantes foram identificados com nome fictício seguido da letra F ou M (feminino ou masculino) entre parênteses. As frases entre colchetes correspondem a esclarecimentos ou intervenções da pesquisadora. 
Nesse sentido, a tendência estereotipada de gênero também foi identificada em relação à questão da escolha profissional, ilustrada nos seguintes exemplos: [Imagine você no futuro. O que precisa fazer para conseguir?] Vin (M) "[quero ser] matador de matar coisas do mal. Com 30 anos, matar bandidos, tem que treinar, lutar com espada e matar com arma" / Pe (M) "jogador de futebol, empinar pipa até ser adulto" / So (F) "uma princesa de contos de fadas com duas coroinhas".

Imaginar-se no futuro é um convite para projetar a si mesmo, o que, indiretamente, vai ao encontro do desejo de crescer. Cabe salientar que, além de serem estereotipadas em relação ao gênero, as produções fantasiosas (princesa, matador) acima apresentadas oferecem indícios do pensamento mágico. Essa indistinção ficção $\times$ realidade resulta relevante porque, em linhas gerais, grande parte das crianças com queixa escolar que chegam ao atendimento por motivos mais ligados a dificuldades cognitivas (em detrimentos das comportamentais) ainda manifesta a prevalência de um pensamento pré-operatório que dificulta a apropriação dos conteúdos do ciclo básico I. É aqui um ponto crucial da interface gênero $\times$ fracasso escolar, que será aprofundado a seguir e que impõe desafios para as educadoras e os educadores.

Várias pesquisas piagetianas verificaram que, durante o período do pensamento intuitivo ou pré-operatório do desenvolvimento, a construção da diferença sexual tende a tomar como base os estereótipos de gênero, como cabelo, roupa e brincadeiras (Kohlberg, 1966; Jagstaidt, 1986; Le Maner, 1997; Garbarino, 2012). Para a maioria das crianças dessa etapa, a genitalidade e os elementos anatômicos secundários, como o peito, não são ainda uma "necessidade lógica" de definição sexual, e a identidade de ser menina ou menino pode mudar conforme as aparências de gênero (Jagstaidt, 1986; Garbarino, 2012). Portanto, para manter a própria identidade do $\mathrm{Eu}$, a criança precisa se "aferrar" a essas atividades, brincadeiras, acessórios e vestimentas classicamente adjudicados ao universo masculino ou feminino. Caso contrário, o Eu se diluiria na ambiguidade sexual, correndo o risco de ser marginalizado e "diferente" dos estereótipos que acalmam e oferecem a acolhida cultural do pertencimento (por exemplo, menino que usa saia, brinca de casinha ou deixa o cabelo comprido vira menina).

Desse modo, além da imersão em um contexto cultural que fomenta a dicotomia, o reducionismo e a rejeição para a diversidade sexual, a tendência infantil de apelar a estereótipos de gênero para definir a identidade sexuada se corresponde também com uma característica do desenvolvimento cognitivo (Kohlberg, 1966; Garbarino, 2012). Assim, ainda que o ambiente seja o fator fundamental para a (des)construção dos estereótipos, o pensamento pré-operatório oferece dificuldades para coordenar e abstrair informações referentes à complexidade da sexualidade humana e à histórica construção binária das identidades de gênero.

Destarte, "ser menino" e "ser menina" ficam atrelados à rigidez da demanda cultural de ser, respetivamente, forte e bela. Os modelos femininos relacionados ao "ser bela" via controle do peso e cuidado do corpo, das unhas e do cabelo (Arbisio, 2007; Gutton, 2009) se apresentam em diversos momentos dos atendimentos. Assim como observado na literatura (Steibel et al., 2011; Souza, 2014), é habitual 
que as meninas cheguem com as unhas pintadas, usando maquiagem, sapato de salto ou diversos acessórios no cabelo etc. A imposição do "ser bela" fica ilustrado na fala de Is $(\mathrm{F})$, quando comenta que pinta as unhas para ir à escola porque "tenho que ir bonita, né?".

A tendência das crianças de 7 a 11 anos de demarcar diferenças de gênero na amizade leva a relações grupais que separam meninos de meninas e fortalece essa divisão estereotipada da imposição de beleza feminina e de força física masculina. A autorrealização e satisfação na vida de grupo, ou seja, a vida similar para todos, é baseada no "querer ser" como os outros (Arbisio, 2007).

Em síntese, e em concordância com o paradigma da intersubjetividade proposto por Golse (2010), o sexismo se enfraquece ou potencializa na retroalimentação das crianças e seu entorno sociocultural, em processos suscitados pela educação. Os estereótipos de gênero são reforçados e valorizados pelos educadores dos âmbitos escolar e familiar, tal como ilustrado na escrita de uma mãe sobre os aspectos positivos de seus filhos (ambos participantes do programa). Diz sobre o menino: "esforçado, dedicado aos esportes", e sobre a menina: "não se envolve em confusão, é carinhosa”, diferença que parece estar permeada pela legitimação dos estereótipos do menino esportista e da menina dócil.

Esses modelos educativos de feminilidade e masculinidade ressoam na construção infantil das identidades de gênero (Reis e Maia, 2009). Entretanto, a dinâmica de circulação do saber e do confronto com outros pontos de vista propiciados pelas rodas de conversa mostra seu potencial de desconstrução, tal como exemplificado na seguinte sequência sobre diferenças entre meninos e meninas: Di $(M)$ "os meninos são mais altos e as meninas são mais pequenas" / Is (F) [responde a $\mathrm{Di}$ ] "mas há homens baixos e meninas altas!" [depois acrescenta] "os homens cozinham mal" $\mathrm{Br}(\mathrm{M})$ [1he responde] "não, meu pai cozinha muito bem, melhor que minha mãe".

Cabe salientar que além dos clichês sexistas perpetuados pelas educadoras e pelos educadores (Moreno, 1999; Reis e Maia, 2009; Madureira e Branco, 2015), a mediação simbólica da palavra fica restrita em modelos educativos em que prevalecem os mecanismos de coação. A fala de Am (F) exemplifica esse mecanismo quando, diante da pergunta "o que você acha muito chato de fazer, mas faz mesmo assim?", diz: "Eu não gosto quando eu quero andar de bicicleta e minha mãe não deixa. Ela tem medo de eu cair e machucar. [E por que você obedece?] Porque eu posso apanhar de cinto".

$\mathrm{Na}$ base da obediência hegemônica, ensina-se a desprezar a discussão como troca simbólica e a calar a singularidade. $\mathrm{Na}$ cronificação dessas práticas, as crianças aprendem a não mediar seus afetos simbolicamente, e a raiva, a tristeza ou a ansiedade se tramitam diretamente no corpo (desde roer as unhas até bater nos outros). Tal como apontado pela literatura, se os meninos apelam à força física como via para resolver conflitos com os pares, não é em função nem da genética, nem do cérebro, nem dos hormônios. A violência física é exacerbada nos processos de socialização primária e secundária de matriz coercitiva que, na contramão da dinâmica das rodas de conversa, limitam o potencial da palavra, da discussão e da expressão de ideias e sentimentos. 


\section{CONSIDERAÇÕES FINAIS}

Desde uma perspectiva empírica, os resultados obtidos neste trabalho visaram contribuir para a discussão das teses frequentes na literatura que buscam explicar a dinâmica das relações entre gênero e fracasso escolar nas últimas décadas. Os dados corroboraram tanto a prevalência de meninos com queixa escolar como o estereótipo masculino de resolução de conflitos interpessoais via agressão física (que responderia ao clássico preconceito do "machão"). Salientou-se que essa distinção na modalidade de afrontamento está relacionada a uma impronta irruptiva de apelação ao corpo associada a questões de gênero, especificamente a representações de masculinidade ligadas à força física. Também os tópicos escolha de preferências lúdicas e escolha vocacional viram-se permeados por esses estereótipos.

Mesmo sendo um tema sem explicações consensuais, e que ainda precisa de mais pesquisas, pode-se afirmar que a manifestação da queixa escolar é sutilmente tonalizada por um modo cultural de entender a distinção masculino $\times$ feminino que se perpetua no contexto escolar. As expectativas e crenças das professoras e dos professores em relação ao ser menino x ser menina permeiam, "contaminam" e "deformam" seu olhar sobre o desempenho e a disciplina das alunas e dos alunos. Portanto, os estereótipos de gênero primeiramente precisam ser identificados para poderem ser desconstruídos. Desse modo, posteriormente, as educadoras e os educadores poderão propiciar propostas pedagógicas que favoreçam sua problematização tanto entre as crianças como na comunidade escolar.

As limitações do presente estudo pautam-se principalmente no tipo de material analisado, que se circunscreve às ações e aos discursos produzidos em um lócus específico de pesquisa no contexto do atendimento de crianças com queixa escolar. Outra restrição a destacar é que o trabalho focalizou a escuta das crianças, sem contemplar a voz das educadoras e dos educadores, tanto da família como da escola. Considera-se, então, a fecundidade de realizar novas investigações que promovam a escuta direta das professoras e dos professores, resgatando o valor das suas crenças, narrativas e vivências no contexto escolar. Além disso, com base no movimento crescente de pesquisas no campo do gênero e do feminismo na educação, são necessários mais estudos que contemplem a pesquisa-ação e o planejamento conjunto de propostas pedagógicas que superem a hegemonia de atividades superficiais, discursivas, prescritivas e moralizadoras que acabam fomentando o respeito heterônomo diante da diversidade de gênero e dos direitos da população LGBT. Em síntese, um dos maiores desafios dos estudos empíricos no campo escolar consiste no progressivo e difícil trabalho de desconstrução da histórica e enraizada naturalização dos estereótipos de gênero no contexto das relações sociais vivenciadas nesse espaço.

Em termos metodológicos, o presente trabalho permitiu concluir que as rodas de conversa constituem instrumentos frutíferos não só para discutir temas como orientação sexual e sexismo, mas também, indiretamente, como estratégia pedagógica que abre espaço para a desconstrução do que se apresenta como óbvio. Ao propiciar o contato com o pensamento livre, prazeroso e autônomo, bases da construção do conhecimento, esse dispositivo traz ganhos para a aprendizagem, para a constituição subjetiva das crianças e para o exercício de reflexão e da cidadania. 
Ainda há muitos interrogantes e tópicos abertos acerca da perpetuação das diferenças de gênero que permeiam a queixa escolar. Essa relação se manifesta explícita, mas, na maioria das vezes, de maneira sutil no microcotidiano da escola, nos discursos, nos gestos e nas crenças sexistas de alunas e alunos, professoras e professores, que ocultam seu carácter de construção sociocultural. Destarte, requer-se um olhar agudizado e crítico para detectar e questionar essas práticas, quase sempre inconscientes. A escola precisa então abrir espaços de fala e escuta às crianças para desentranhar os estereótipos e clichês do ser menino e ser menina.

Nesse sentido, no dispositivo das rodas de conversa, "o outro" confronta e amplifica o pensar, com alternativas que podem ser impensadas ou indizíveis para um sujeito. É nesse âmbito que o outro funciona como estrangeiro (Kristeva, 1998) e a intervenção de cada criança pode diversificar os lugares-comuns. A experiência da troca de pontos de vista se enriquece quando o sujeito se posiciona no ato de enunciar, evitando ficar preso à repetição de enunciados feitos e problematizando o que até então parecia não ir além do já conhecido e repetido. A dicotomia reducionista dos estereótipos femininos $\times$ masculinos e seus clássicos universos estáticos do ser menino $\mathrm{x}$ menina constituem uma das tantas temáticas que se apresentam como "óbvias e naturais". Nesse sentido, a relação gênero e queixa escolar pode ser problematizada ao colocar em xeque sua reificação, salientando que ambas são construções sociais e, portanto, podem ser mudadas. É então nesse movimento de trocas com a alteridade que algo do histórico laço entre gênero e fracasso escolar poderá ser desconstruído, porque, quando o mundo deixa de ser um lugar de evidências, torna-se mais complexo e atrativo de aprender e transformar.

\section{REFERÊNCIAS}

ALTMANN, H. Orientação sexual nos países curriculares nacionais. Revista Estudos Feministas, Florianópolis, v. 9, n. 2, p. 575-585, 2001. Disponível em: http://www. scielo.br/scielo.php?script=sci_arttext\&pid=S0104-026X2001000200014\&lng=en\&nr $\mathrm{m}=$ iso. Acesso em: 18 jun. 2018. https://doi.org/10.1590/S0104-026X2001000200014 ALTMANN,H.Educação sexual em uma escola: da reprodução à prevenção. Cadernos de Pesquisa, São Paulo, v. 39, n. 136, p. 175-200, abr. 2009. Disponível em: http://www. scielo.br/scielo.php?script=sci_arttext\&pid=S0100-15742009000100009\&lng=en\&nr $\mathrm{m}=$ iso. Acesso em: 16 maio 2018. https://doi.org/10.1590/S0100-15742009000100009 ALVES, L.; CARVALHO, A. M. Videogame: é do bem ou do mal? Como orientar pais. Psicologia em Estudo, Maringá, v. 16, n. 2, p. 251-258, jun. 2011. Disponível em: http:// www.scielo.br/scielo.php?script=sci_arttext\&pid=S1413-73722011000200008\&ln $\mathrm{g}=$ en\&nrm=iso. Acesso em: 25 abr. 2019. https://doi.org/10.1590/S141373722011000200008

ALVES, M.T.G.; SOARES,J. F. Contexto escolar e indicadores educacionais: condições desiguais para a efetivação de uma política de avaliação educacional. Educação e Pesquisa, São Paulo, v. 39, n. 1, p. 177-194, mar. 2013. Disponível em: http://www. scielo.br/scielo.php?script=sci_arttext\&pid=S1517-97022013000100012\&lng=en\&nr m=iso. Acesso em: 24 abr. 2019. https://doi.org/10.1590/S1517-97022013000100012 
ARBISIO, C. L'enfant de la période de latence. 2. ed. Paris: Dunod, 2007. BAUTHENEY, K. C. S. F. Transtornos de aprendizagem: quando "ir mal na escola" torna-se um problema médico e/ou psicológico. 2011. Tese (Doutorado em Educação) - Programa de Pós-Graduação em Educação, Faculdade de Educação, Universidade de São Paulo, São Paulo, 2011.

BIANCHI, E.; FARAONE, S.A. El Trastorno por Déficit de Atención e Hiperactividad (TDA/H). Tecnologías, actores sociales e industria farmacéutica. Physis, Rio de Janeiro, v. 25, n. 1, p. 75-98, mar. 2015. https://doi.org/10.1590/S0103-73312015000100006 BONADIO, R. A. A.; MORI, N. N. R. Transtorno de déficit de atenção/ hiperatividade: diagnóstico da prática pedagógica. Maringá: Eduem, 2013.251 p. BORSA, J. C.; SOUZA, D. S.; BANDEIRA, D. R. Prevalência dos problemas de comportamento em uma amostra de crianças do Rio Grande do Sul.Psicologia:Teoria e Prática, São Paulo, v. 13, n. 2, p. 15-29, ago. 2011. Disponível em: http://pepsic. bvsalud.org/scielo.php?script=sci_arttext\&pid=S1516-36872011000200002\&lng=pt \&nrm=iso. Acesso em: 22 abr. 2019.

BRANCO, P. I.; PAN, M. A. G. S. Rodas de conversa: uma intervenção da psicologia educacional no curso de medicina. Psicologia: Teoria e Prática, São Paulo, v. 18, n. 3, p. 156-167, dez.2016. Disponível em: http://pepsic.bvsalud.org/scielo.php?script=sci_ arttext\&pid=S1516-36872016000300012\&lng=pt\&nrm=iso. Acesso em:17 abr. 2019. https://doi.org/10.5935/1980-6906/psicologia.v18n3p156-167

BROUGÈRE, G.Les expériences ludiques des filles et des garçons. In: LEMEL,Y;;ROUDET, B. (org.). Filles et Garçons Jusqu'al'adolescence. Paris: L'Harmattan, 1999. p. 25-56.

CADETE, V. G.; FERREIRA, S. P. A.; SILVA, D. B. Os sentidos e os significados produzidos pela escola em relação à família homoparental: um estudo de caso. Interação em Psicologia, Curitiba, v. 16, n. 1, p. 101-112, jun. 2012. Disponível em: https:// revistas.ufpr.br/psicologia/article/view/13947. Acesso em: 16 maio 2019. https://doi. org/10.5380/psi.v16i1.13947

CAHILL, L. His brain, her brain. ScientificAmerican, out. 2012. Disponível em: https:// www.scientificamerican.com/article/his-brain-her-brain-2012-10-23/?redirect=1. Acesso em: 1 jun. 2018.

CAMARGO, A.; RIBEIRO, C. Sexualidade(s) e infância(s): a sexualidade como um tema transversal. São Paulo: Moderna, 1999.

CARVALHO, M. P. Mau aluno, boa aluna? Como as professoras avaliam meninos e meninas. Revista Estudos Feministas, Florianópolis, v. 9, n. 2, p. 554-574, dez. 2001. https://doi.org/10.1590/S0104-026X2001000200013

CARVALHO, M. P. Sucesso e fracasso escolar: uma questão de gênero. Educação e Pesquisa, v. 29, n. 1, p. 185-193, jun. 2003. Disponível em: https://www.scielo.br/scielo. php?script=sci_arttext\&pid=S1517-97022003000100013\&lng=pt\&tlng=pt. Acesso em: 22 abr. 2019. https://doi.org/10.1590/S1517-97022003000100013

CARVALHO, M. P. O fracasso escolar de meninos e meninas: articulações entre gênero e cor/raça. Cadernos Pagu, Campinas, n. 22, p. 247-290, jun. 2004. Disponível em: http://www.scielo.br/scielo.php?script=sci_arttext\&pid=S0104- 
83332004000100010\&lng=en\&nrm=iso. Acesso em: 17 abr. 2019. https://doi. org/10.1590/S0104-83332004000100010

CARVALHO, M. P. Teses e dissertações sobre gênero e desempenho escolar no Brasil (1993-2007): um estado da arte. Pro-Posições, v. 23, n. 1, p. 147-161, abr. 2012. Disponível em: https://periodicos.sbu.unicamp.br/ojs/index.php/proposic/article/ view/8643231. Acesso em: 17 abr. 2019.

CARVALHO, M. P.; SENKEVICS, A. S.; LOGES, T. A. O sucesso escolar de meninas de camadas populares: qual o papel da socialização familiar? Educação e Pesquisa, São Paulo, v. 40, n. 3, p. 717-734, set. 2014. https://doi.org/10.1590/s1517-97022014091637 CASTRO, T. G.; ABS, D.; SARRIERA, J. C. Análise de conteúdo em pesquisas de Psicologia. Psicologia: Ciência e Profissão, Brasília, v. 31, n. 4, p. 814-825, 2011. Disponível em: http://www.scielo.br/scielo.php?script=sci_arttext\&pid=S141498932011000400011\&lng=en\&nrm=iso. Acesso em: 24 abr. 2019. https://doi. org/10.1590/S1414-98932011000400011

CECHIN, M. B. C.; SILVA, T. Assim falava Barbie: uma boneca para todos e para ninguém. Fractal: Revista de Psicologia, Rio de Janeiro, v. 24, n. 3, p. 623-638, dez. 2012. Disponível em: http://www.scielo.br/scielo.php?script=sci_arttext\&pid=S198402922012000300012\&lng=en\&nrm=iso. Acesso em: 22 abr. 2019. https://doi. org/10.1590/S1984-02922012000300012

EMERICH, D. R. et al. Diferenças quanto ao gênero entre escolares brasileiros avaliados pelo inventário de comportamentos para crianças e adolescentes (CBCL/6-18). Psico, v. 43, n. 3, p. 380-387, 2012. Disponível em: http://revistaseletronicas.pucrs.br/ojs/index. php/revistapsico/article/view/10053. Acesso em: 2 abr. 2019.

FIGUEIRÓ, M. Educação sexual: múltiplos temas, compromisso comum. Londrina: UEL, 2009.

FOUCAULT, M. História da sexualidade: a vontade de saber. 6. ed. Rio de Janeiro: Graal, 2010.v. 1.

GARBARINO, M. I. Crenças sobre a origem dos bebês em crianças de 4 a 9 anos: uma abordagem a partir da psicogênese piagetiana e da psicanálise freudiana. 2012. Dissertação (Mestrado em Psicologia Escolar e do Desenvolvimento Humano) Universidade de São Paulo, São Paulo, 2012.

GARBARINO, M. I. Construção do prazer de pensar e desenvolvimento: um estudo teórico-clínico com crianças em dificuldade escolar. 2017. Tese (Doutorado em Psicologia Escolar e do Desenvolvimento Humano) - Universidade de São Paulo, São Paulo, 2017.

GOLSE, B. Les destins du développement chez l'enfant. Toulouse: Eres, 2010.

GUARIDO, R. A medicalização do sofrimento psíquico: considerações sobre o discurso psiquiátrico e seus efeitos na educação. Educação e Pesquisa, São Paulo, v. 33, n. 1, p. 151-161, abr. 2007. Disponível em: http://www.scielo.br/scielo.php?script=sci_ arttext\&pid=S1517-97022007000100010\&lng=en\&nrm=iso. Acesso em: 24 abr. 2019. https://doi.org/10.1590/S1517-97022007000100010

GUIMARÃES, I. Educação sexual na escola: mito e realidade. Campinas: Mercado de Letras, 1995. 
GUTTON, P. Le jeu chez l'enfant. Paris: Larousse, 2009.

HIRATA, H. Nova divisão sexual do trabalho? São Paulo: Boitempo, 2002.

HOUDÉ, O. Le raisonnement. Paris: Puf, 2014. (Coleção Que sais-je?).

JAGSTAIDT, V. A sexualidade e a criança. São Paulo: Manole, 1986.

JANÍN, B. Niños desatentos e hiperactivos: reflexiones críticas acerca del trastorno por déficit de atención con o sin hiperactividad. Buenos Aires: Novedades Educativas, 2004.

KOHLBERG, L. A cognitive developmental analysis of children's sex role concepts and attitudes. In: MACCOBY,J. (org.). The development of sex differences. Stanford: Stanford University Press, 1966. p. 239-252.

KRISTEVA, J. Sentido y sinsentido de la revuelta. Buenos Aires: Eudeba, 1998.

LEE, F. I.; MATARAZZO, E. B. Prevalência de adoção intra e extrafamiliar em amostras clínica e não-clínica de crianças e adolescentes. Revista Brasileira de Psiquiatria, São Paulo, v. 23, n. 3, p. 149-155, set. 2001. https://doi.org/10.1590/S1516-44462001000300007

LE MANER, G. Lidentité sexuée. Paris: Dunod, 1997.

LENOBLE, É. La langue à l'épreuve du scolaire: que nous apprennent les enfants en mal de lecture et d'écriture? Enfances \& Psy, v. 2, n. 47, p. 128-140, 2010. Disponível em: https://www.cairn.info/journal-enfances-et-psy-2010-2-page-128.htm. Acesso em: 24 abr. 2019. https://doi.org/10.3917/ep.047.0128

MADUREIRA, A. F. A.; BRANCO, A. U. Gênero, sexualidade e diversidade na escola a partir da perspectiva de professores/as. Temas em Psicologia, Ribeirão Preto, v. 23 , n. 3, p. 577-591, set. 2015. Disponível em: http://pepsic.bvsalud.org/scielo. php?script=sci_arttext\&pid=S1413-389X2015000300005\&lng=pt\&nrm=iso. Acesso em: 24 abr. 2018. https://doi.org/10.9788/TP2015.3-05

MARANGON, C. Alicia Fernandez: aprendizagem também é uma questão de gênero. Nova Escola, n. 207, nov. 2007. Disponível em: https://novaescola.org.br/conteudo/867/ alicia-fernandez-aprendizagem-tambem-e-uma-questao-de-genero. Acesso em:24 abr.2019. MELO, R. H. V. et al. Roda de conversa: uma articulação solidária entre ensino, serviço e comunidade. Revista Brasileira de Educação Médica, Rio de Janeiro, v. 40, n. 2, p. 301-309, jun. 2016. Disponível em: http://www.scielo.br/scielo.php?script=sci_ arttext\&pid=S0100-55022016000200301\&lng=en\&nrm=iso. Acesso em: 17 abr. 2019. https://doi.org/10.1590/1981-52712015v40n2e01692014

MOIZÉS, J. S.; BUENO, S. M. V. Compreensão sobre sexualidade e sexo nas escolas segundo professores do ensino fundamental. Revista da Escola de Enfermagem da USP, São Paulo, v. 44, n. 1, p. 205-212, mar. 2010. Disponível em: https://www.scielo. br/scielo.php?pid=S0080-62342010000100029\&script=sci_abstract\&tlng=pt. Acesso em: 24 abr. 2019. https://doi.org/10.1590/S0080-62342010000100029

MORENO, M. Como se ensina a ser menina: o sexismo na escola. São Paulo: Moderna, 1999.

NUNES, C.; SILVA, E. A educação sexual da criança. Campinas: Autores Associados, 2000. OSTI, A.; BRENELLI, R. Sentimentos de quem fracassa na escola: análise das representações de alunos com dificuldades de aprendizagem. Psico-USF, Itatiba, v. 18, 
n. 3, p. 417-426, dez.2013. Disponível em: http://www.scielo.br/scielo.php?script=sci_ arttext\&pid=S1413-82712013000300008\&lng=en\&nrm=iso. Acesso em:24 abr. 2019. https://doi.org/10.1590/S1413-82712013000300008

PARISOTTO, L. et al. Diferenças de gênero no desenvolvimento sexual: integração dos paradigmas biológico, psicanalítico e evolucionista. Revista de Psiquiatria do Rio Grande do Sul, Porto Alegre, v. 25, supl. 1, p. 75-87, abr. 2003. Disponível em: http://www.scielo. $\mathrm{br} /$ scielo.php?script=sci_arttext\&pid=S0101-81082003000400009\&lng=en\&nrm=iso. Acesso em: 16 maio 2019. https://doi.org/10.1590/S0101-81082003000400009

REIS, K.; MAIA, A. Estereótipos sexuais e a educação sexista no discurso de mães. In: VALLE, T. G. M. (org.). Aprendizagem e desenvolvimento humano: avaliações e intervenções. São Paulo: Cultura Acadêmica, 2009. p. 137-154.

REZENDE, A. R. T. Dificuldades aritméticas em indivíduos com transtorno do déficit de atenção/hiperatividade: avaliação clínica e por neuroimagem funcional.2013. Tese (Doutorado em Neurologia) - Faculdade de Medicina, Universidade de São Paulo, São Paulo, 2013.

ROHDE, L. A.; HALPERN, R. Transtorno de déficit de atenção/hiperatividade: atualização. Jornal de Pediatria, Porto Alegre, v. 80, n. 2, p. 61-70, abr. 2004. Disponível em: http://www.scielo.br/scielo.php?script=sci_arttext\&pid=S0021$75572004000300009 \& \operatorname{lng}=$ en\&nrm=iso. Acesso em: 24 abr. 2019. https://doi. org/10.1590/S0021-75572004000300009

ROSSETTI, C. B.; SOUZA, M.T.C. C. Preferência lúdica de uma amostra de crianças e adolescentes da cidade de Vitória. Psicologia: Teoria e Prática, São Paulo, v. 7, n. 2, p. 87-114, dez. 2005. Disponível em: http://pepsic.bvsalud.org/scielo.php?script=sci_ arttext\&pid=S1516-36872005000200004\&lng=pt\&nrm=iso. Acesso em:25 abr. 2019. SAMPAIO, J. et al. Limites e potencialidades das rodas de conversa no cuidado em saúde: uma experiência com jovens no sertão pernambucano. Interface, Botucatu, v. 18, supl.2,p.1299-1311,2014. Disponível em: http://www.scielo.br/scielo.php?script=sci_ arttext\&pid=S1414-32832014000601299\&lng=en\&nrm=iso. Acesso em:17 abr. 2019. https://doi.org/10.1590/1807-57622013.0264

SILVEIRA, R.M.H.; KAERCHER, G. E. S. Dois papais, duas mamães: novas famílias na literatura infantil. Educação \& Realidade, Porto Alegre, v. 38, n. 4, p. 1191-1206, dez. 2013. https://doi.org/10.1590/S2175-62362013000400010

SIQUEIRA, C.M.; GURGEL-GIANNETTI,J. Mau desempenho escolar: uma visão atual. Revista da Associação Médica Brasileira, São Paulo, v. 57, n. 1, p. 78-87, fev. 2011. Disponível em: http://www.scielo.br/scielo.php?script=sci_arttext\&pid=S010442302011000100021\&lng=en\&nrm=iso. Acesso em: 24 abr. 2019. https://doi. org/10.1590/S0104-42302011000100021

SOUZA, A. S.L. Re-visitando a latência: reflexões teórico-clínicas sobre os caminhos da sexualidade. Psicologia USP, São Paulo, v. 25, n. 2, p. 155-161, ago. 2014. Disponível em: http://www.scielo.br/scielo.php?script=sci_arttext\&pid=S0103-65642014000200155\&ln $\mathrm{g}=\mathrm{en} \& \mathrm{nnm}=\mathrm{iso}$. Acesso em: 16 maio 2019. https://doi.org/10.1590/0103-656420130003 STEIBEL, D. et al. A latência na atualidade: considerações sobre crianças encaminhadas para psicoterapia. Aletheia, Canoas, n. 35-36, p. 51-68, dez. 2011. Disponível em http:// 
pepsic.bvsalud.org/scielo.php?script=sci_arttext\&pid=S1413-03942011000200005\&ln $\mathrm{g}=\mathrm{pt \& nrm}=\mathrm{iso}$. Acesso em: 16 maio 2019.

SUZUKI, F. T. I. et al. O uso de videogames, jogos de computador e internet por uma amostra de universitários da Universidade de São Paulo. Jornal Brasileiro de Psiquiatria, Rio de Janeiro, v. 58, n. 3, p. 162-168, 2009. Disponível em: http://www. scielo.br/scielo.php?script=sci_arttext\&pid=S0047-20852009000300004\&lng=en\&nr $\mathrm{m}=$ iso. Acesso em: 16 maio 2019. https://doi.org/10.1590/S0047-20852009000300004 TOKARNIA, M. Governo quer localizar 1,6 milhão de alunos que deixaram a escola em 2015. UOL, 6 maio 2016. Disponível em: https://educacao.uol.com.br/ noticias/2016/05/06/governo-quer-localizar-16-milhao-de-alunos-que-deixaram-aescola-em-2015.htm?cmpid=copiaecola. Acesso em: 24 abr. 2019.

URRIBARRI, R. Estruturação psíquica e subjetivação da criança em idade escolar. São Paulo: Escuta, 2012.

VIANNA, C. Gênero, sexualidade e políticas públicas de educação: um diálogo com a produção acadêmica. Pro-Posições, Campinas, v. 23, n. 2, p. 127-143, ago. 2012. Disponível em: https:/www.scielo.br/pdf/pp/v23n2/a09v23n2.pdf. Acesso em: 24 abr. 2019. https://doi.org/10.1590/S0103-73072012000200009

WESTLY, E. Different shades of blue. Scientific American, out. 2012. Disponível em: https:/www.scientificamerican.com/article/different-shades-of-blue-2012-10-23/. Acesso em: 16 maio 2018.

ZULUETA, A. L. Logros y fracasos de la latencia como parámetros del diagnóstico clínico. Psicopatología y Salud Mental, v. 16, p. 21-28, 2010. Disponível em: http:// www.fundacioorienta.com/logros-y-fracasos-de-la-latencia-como-parametros-deldiagnostico-clinico/. Acesso em: 15 maio 2019.

\section{SOBRE A AUTORA}

Mariana Inés Garbarino é doutora em psicologia escolar e do desenvolvimento humano pela Universidade de São Paulo (USP). Professora da Universidade Federal de São Paulo (UNIFESP). E-mail:marianaigarbarino@gmail.com

Conflitos de interesse: A autora declara que não possui nenhum interesse comercial ou associativo que represente conflito de interesses em relação ao manuscrito.

Financiamento: Coordenação de Aperfeiçoamento de Pessoal de Nível Superior (CAPES). 